\title{
How to Realize Reverse Logistics Cost Control of Chain Enterprises
}

\author{
Xiaoyan Zhu, Xinmeng Li \\ Yantai Nanshan University, Yantai, 265713, China
}

\begin{abstract}
Keywords: Chain enterprises, Reverse Logistics, Cost control
\end{abstract}
\begin{abstract}
During the production and operation process of enterprises, reverse logistics is an inevitable link, it will exist, no matter for their own wish or for the pressure of competition, or for the government' s force control. While, some people think reverse logistics will increase the operating cost of the enterprise, and b ring many unfavorable effects. Throughout analysis, we get that though reverse logistics increase operation cost to a certain extent and during a certain period, but from long run, it will bring the enterprise strategic value. In this paper, author will start with the reverse logistics of chain enterprises to explore policies for cost control of logistics, to make contributions for the sustainable development of chain enterprises.
\end{abstract}

\section{Introduction}

Reverse logistics of chain enterprises means that in the operation process of enterprises, there will be damaged, unsalable or wasted products, which need to be sent back from the consuming link to the distribution center, then be centralized processing. This process from commodity recycling to processing is reverse logistics.

\section{Analysis on the logistics frame of chain enterprises}

\section{Types of reverse logistics of chain enterprises}

Reverse logistics of chain enterprises are mainly divided in to three types:

Reverse logistics caused by consumers

1). Return of goods. Return of goods is an inevitable phenomenon in the sales process of enterprises. In modern society, people' s consumption trends to be more and more diverse, consumers' taste also changed a lot, which will cause return of goods easily ${ }^{[1]}$. Besides, acceleration of commodity production leads to different kinds of problems of the product, which is also the main reason for the return of goods.

2). Recycle when goods lost its value. Now, with the accelerating pace of economic development, problems of environment pollution and resource shortage continuously appear. In order to deal with the strict resource situation, more and more countries begin to pay attention to recycling of waste goods. Therefore, the development of this industry cannot only save resource for national development, but also reduce the production cost of enterprises. Besides that, recycle waste goods can increase enterprises' social responsibility and establish brand image to enhance their fame. When face these benefits, enterprises will be also active to recycle waste goods.

3). Change and maintenance. It is inevitable to appear defect or damaged products during the production process of enterprises, when this problem happens, responsible enterprises will provide free maintenance service for customers to improve customer satisfaction and competitiveness.

4). Recycle of packing materials. For enterprises' development, recycle of the packing material is very useful, it can maximum reduce enterprises' production cost and also relieve social problems of resource shortage, it is also benefit to the development of our country and the whole society.

Reverse logistics caused by retail stores

1). Return of unmarketable goods. During the sales process, there will be goods hoarding for enterprises' inadequate market survey or the wrong store data processing, which is easy to make holdup of the commodity, then make reverse logistics. 
2). Wrong delivery. Wrong delivery caused by wrong information also will lead to reverse logistics.

Reverse logistics caused by distribution center

1). There are many cyclical commodities appear in the production process, these commodities need to be updated or weeded out ${ }^{[2]}$ for a period of time, this also cause reverse logistics.

2). Damage of commodities will be caused by improper transportation ways when the in the process of delivery from the distribution center, and all these damaged commodities will be sent back to enterprises, this also will cause reverse logistics.

\section{Steps of reverse logistics of the chain enterprises}

Enterprises will get through the following steps when reverse logistics happens:

1). Consumer-retail store: consumer returns goods to the store for goods quality or personnel preference, store collects return goods, goods need repairmen and waste goods from the consumer.

2). Retail store $\rightarrow$ distribution center: retail store sent back the return goods, goods need repairmen and waste goods from the consumer to the distribution center. Distributor will again deliver the repaired goods to the retail store, at the same time it will centralize to process goods and waste materials that no need to deliver again.

3). Distribution center $\rightarrow$ supplier: distribution center returns the goods need maintenance or goods cannot sale again to the supplier, supplier destroy it.

4). Retail store $\rightarrow$ supplier: retail store can directly return goods with problems to the supplier.

5). Retail store $\rightarrow$ retail store: retail stores can change goods directly.

\section{Reverse logistics frame of chain enterprises}

Throughout analysis on the logistics frame of chain enterprises, get the following frame. Figure 1:

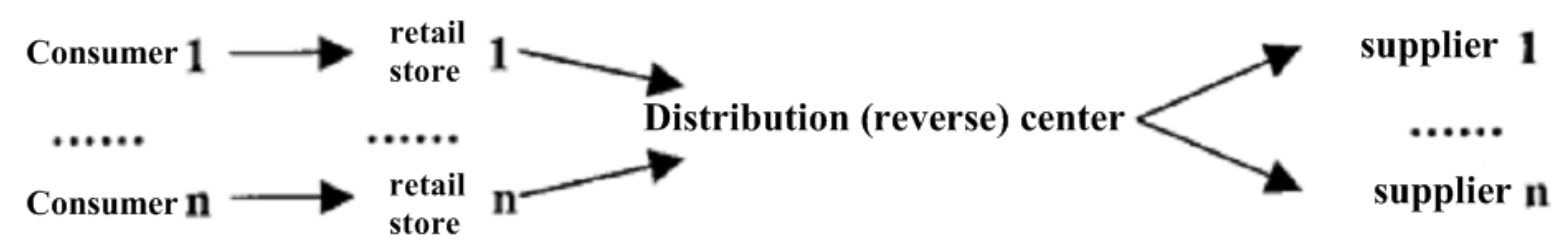

Fig. 1. Reverse logistics frame of chain enterprises

\section{Reverse logistics cost and strategy value of chain enterprises}

\section{Analysis on the reverse logistics cost of chain enterprises}

Cost brought by content

1). Transportation cost. Reverse logistics will produce some cost during the transportation process, for example, if the return goods is just a little, it will make special transportation cost; in the process of transportation, bad transportation condition also will cause damage to the package to cause some unnecessary loss; there also have some transportation caused by the disparity of time and place.

2). Cost for sorting and distribution. Distribution center will increase $\operatorname{cost}^{[3]}$ on sorting and distribution for the return goods is not in large scale. Besides that, damage on the goods package will increase unnecessary trouble for workers, this also will increase cost.

3). Warehouse cost. Return goods will occupy the warehouse, this also cause the waste of warehouse stock to increase cost.

Cost caused by different links

1). Operation features of chain enterprises. Chain enterprises have the features of scale and decentralization. Scale means retail stores of chain enterprises are operated in scale mode, while decentralization means disparity in places. Therefore, in the reverse logistics, relevant staffs need to do goods return collection process, which increased cost. 
2). Distribution feature of chain enterprises. For chain enterprises, goods distribution is arranged by the headquarter, this will cause the unreasonable phenomenon of goods distribution, retail store need to return the surplus and wrong goods to the distribution center, then cause cost increase.

3 ). The processing characteristics of distribution center. Distribution center need to sort out the return goods, resend goods that can be modified, centralized process the goods that cannot be modified, or send back to headquarter, this link also cause cost waste.

\section{Value of the reverse logistics}

Help enterprises to retain customers

Reverse logistics can help enterprises to establish reputation, improve customer satisfaction, so as to increase customers' loyalty ${ }^{[4]}$ to the enterprise brand. For customers, reverse logistics can not only help them change the unsatisfied commodities, and also reduce their purchase risk to improve their loyalty.

Improve competitive advantage of enterprises

Reverse logistics can directly connect with service quality. Its successful operation can help enterprises reduce economic loss, and improve service quality to improve their competitive advantage.

Enhance inner management ability of enterprises

Inner management code of chain enterprises is a closed link, it includes: production plan, production implement, checking and accepting and improve insufficient. While, reverse logistics connects the check and improvement processes. Enterprises can effectively collect reasons and total cost of reverse logistics through check and improvement, and based this to improve management process.

Establish enterprises image

With the continuous development of economic society, people are paying more attention to enterprises' response to social responsibility. In modern society, the problem of environment pollution and resource shortage become more and more serious, enterprises' attitude to these problems directly affects their image. Reverse logistics can help enterprises gain more praise and help them to establish a better image.

\section{Construction and cost control of reverse logistics of chain enterprises}

Reverse logistics of chain enterprises need to be constructed and controlled from two aspects:

\section{Build logistics operation system}

Set reverse logistics area

Set forward logistics and reverse logistics areas in the distribution center ${ }^{[5]}$, during the process of forward logistics, send back goods of reverse logistics, and centralize the return goods to the reverse logistics area to process. The function of reverse logistics area is to effectively use transportation, warehouse, handling facilities and human resources under the original distribution link, and try to guarantee work efficiency as well as save distribution costs.

Set up reverse logistics processing center

Chain enterprises should build an inner independent reverse logistics processing center. This processing center is specialized organization for reverse logistics. Therefore, its operation should be operated from the forward logistics, or even in the same organization, they should be operated in two systems. The purpose is to guarantee the convenient operation of reverse logistics, and to avoid unnecessary troubles.

Main responsibilities of the reverse logistics processing center are:

1).Receiving return goods from the retail stores;

2). Identify the types of return goods and process it; 
3). Make statistic analysis for the reason, number and trends of return goods, and provide relevant reports to the enterprise. Enterprise can make feedback based on this report to reduce return goods from retail stores, decrease retail stores' cost of loss, and improve their profit.

Chain enterprises entrust reverse logistics company to escrow

Professional reverse logistics company brings enterprises with new opportunity. Professional reverse logistics company performs noticeably well, no matter from their profession degree or their scientific management. Its appearance promotes reverse logistics management up to a new stage.

Professional reverse logistics company has many advantages, mainly manifests as: (1) Make reverse logistics form scale, enhance cost advantage of enterprise transportation. Professional reverse logistics company can collect, classify, store and process return goods more effectively, and standardize enterprise operation to reduce their cost; (2) More detailed labor division of reverse logistics makes higher work efficiency. Professional reverse logistics company sets up many branches, such as reverse logistics transportation company, storage company, repairing company, centralized processing company and so on. These companies undertake their own tasks, which not only improved work efficiency, but also reduced reverse logistics cost; (3) More perfect management. Administrative staffs in the professional reverse logistics company are more professional, this can help enterprises deal with reverse logistics problems and save unnecessary loss.

\section{Establish reverse logistics information system}

\section{Strengthen the collection and storage of return goods information}

Reverse logistics company must record the source of return goods, and collect product information, stock information and financial information, at last transfer collected information into data for storage. When collect and store information of return goods, they can integrate new information with historical information by using data warehouse technology to analyze the reason for goods return, then to reduce cost caused by good return, and to improve enterprises' operation profit and reduce operation risk.

\section{Analyze and model collected data}

The purpose of establishing reverse logistics database is to reduce production risk and operation cost of enterprises, to improve their return rate. Analyze data by using reverse logistics information system, which can transfer the collected data information into reverse logistics knowledge and construct reverse logistics mode to guide reverse logistics in the future.

Increase application and share of data information

Reverse logistics information can be written into report after integrated, and sent to the company headquarter. After receiving the report, headquarter can analyze the reverse logistics data in details to adjust the quality and performance of new products. At the same time, reverse logistics can also provide reference for the transportation of new products, and provide suppliers and retail stores with information of product quality and marketing. Therefore, they can reduce cost caused by goods return/change for the problem of the product itself when effectively increase business volume of the retail stores.

\section{Conclusion}

With the rapid development of world industrial process, the phenomenon of environment pollution and resource waste is becoming more and more severe. In order to deal with the current severe situation, many countries put forward a lot of sustainable development strategies. Reverse logistics raises people' s attention under this background. From then, researches on reverse logistics around the world is increasing, many chain enterprises also changed their former views and began to pay attention to the reverse logistics. Researches showed that reverse logistics is very good for the development of chain enterprises, it can help them to reduce operation cost, enhance profitability, and gain competitiveness, final to realize the development target of the enterprises. 


\section{References}

[1] Wang Xiaotan, Reverse logistics distribution cost optimization of large-scale commercial chain enterprises under the background of urbanization. Logistics technology, 2014,33(4):41-42,56.

[2] Zhang Jing, Analysis on the reverse logistics of household appliance chain enterprises' distribution center. Hennan science and technology, 2014(8):232

[3] Li Bin, Study on the legal issues in the reverse logistics of chain enterprises. Logistics technology, 2012,31(7):149-151.

[4] Sun Wenpeng. Study on the optimization of logistics system of chain super market. Tianjin University of technology, 2014

[5] Wen Lei, Guide analysis of the strategy value for enterprises to implement reverse logistics. Economic questions, 2014(11):75-78. 